\title{
Familiarity effects in a same-different task with simultaneous and successive presentation
}

\author{
CAROL I. YOUNG and MILTON H. HODGE \\ University of Georgia, Athens, Georgia 30602
}

\begin{abstract}
To assess conflicting results of prior studies concerned with the effects of familiarity and task conditions on the performance of visual matching tasks, six groups of independent observers $(\mathrm{N}=8)$ each received three blocked trials of 12 "same" and 12 "different" pairs (randomly ordered) of letters, rotated letters, or nonsense forms presented simultaneously or successively in a tachistoscope. Each observer was asked to judge whether the elements of each pair were "same" or "different." Analysis of the RTs showed that judgments of the nonsense forms were slower than the equally fast responses to the letters and rotated letters. An interaction between presentation mode and type of stimulus pair indicated that judgments of "same" pairs were somewhat faster with successive than with simultaneous presentation, but "different" pairs were judged equally fast under both modes. The results are related to earlier studies of familiarity, but emphasis is placed on a facilitation hypothesis based on meaningfulness.
\end{abstract}

It is widely appreciated that familiar stimuli are more easily recognized and processed than are unfamiliar stimuli, but there is little agreement on the mechanisms or processes that mediate these effects. Some investigators have suggested that familiarity affects the way we actually perceive the world (e.g., Hebb, 1972); others have contended that it influences nonperceptual factors such as memory and processing strategies (e.g., Hochberg, 1968). A recent analy'sis of the possible loci of familiarity effects can be found in Krueger (1975).

Laboratory studies of familiarity have often used a matching task in which an observer is asked to judge whether two simultaneously presented stimuli are physically identical. In experiments with single-letter and letter-like stimuli, familiarity has been manipulated in three ways: (1) normally oriented vs. rotated letters, (2) letters vs. letter-like nonsense forms, and (3) induction of familiarity by repeating certain stimuli more frequently than others or by using stimuli that vary in frequency of occurrence in English. These different definitions, along with varying task characteristics, appear responsible in part for the mixed results of a number of familiarity studies. With observers given extensive pretraining, Posner and Mitchell (1967) found no difference in the speed of physical matching for letters and Gibson nonsense figures. When Robinson (1969) defined familiarity in terms of number of exposures of unfamiliar Chinese characters, performance of "different" pairs improved over trials, but that of "same" pairs did not. Egeth and Blecker (1971), on the other hand, with normal and inverted letters, showed

This research was conducted by the first author in partial fulfillment of the master's degree under the supervision of the second author. Requests for reprints should be sent to Milton $\mathrm{H}$. Hodge, Department of Psychology, University of Georgia, Athens, Georgia 30602. that familiarity facilitated only "same" judgments. Krueger (1973) varied familiarity by use of normal and rotated letters (in blocked trials) and by repeating certain pairs over trials. Both "same" and "different" pairs were affected by frequency of presentation, but only marginally by letter orientation. Ambler and Proctor (1976) tested the hypothesis that presenting familiar and unfamiliar stimuli together (mixed trials) confounds perceptual effects with processing strategies. When both familiar and unfamiliar stimuli were presented in mixed trials, a familiarity effect was obtained in the "same" judgments, but not when the familiar and unfamiliar stimuli occurred in blocked trials.

Thus, the familiarity effect in visual matching tasks apparently depends on: (1) the nature of the stimuli, (2) the frequency of stimulus presentation, and (3) whether stimuli occur in mixed or blocked trials. In addition, another possible factor is whether stimuli are presented simultaneously or successively. Hochberg (1968) displayed familiar and unfamiliar letter strings that could or could not be seen in one fixation and found no difference when both elements of a stimulus pair could be seen simultaneously. However, when the elements were shown successively, presumably imposing a memory requirement, the familiar strings were responded to more easily than the unfamiliar ones.

The present experiment sought to (1) test whether the various familiarity manipulations are equivalent, (2) test Hochberg's (1968) hypothesis that the imposition of short-term memory (STM) will produce a performance decrement with unfamiliar but not with familiar stimuli, and (3) control processing strategies. Familiarity was varied by reorienting letters and by use of nonsense forms. All stimuli were repeated to assess the effects of practice. Both simultaneous and successive 
presentation were used to evaluate the influence of memory. And, in response to Ambler and Proctor's (1976) criticism of mixed trials, each observer was shown only one type of stimulus in one presentation mode.

\section{METHOD}

\section{Materials and Apparatus}

The stimuli were letters, rotated letters, and nonsense forms. The latter were forms freely adapted from sources with which native English readers have had little experience (e.g, Gibson forms and the Chinese, Japanese, and Cyrillic alphabets). Informal pretesting resulted in 24 forms. Thirty independent subjects each rated either the association value ("Does the form remind you of a letter or other common symbol?") or the similarity of each form to letters (a 5-point similarity-dissimilarity scale was used). Although the original goal was to design stimuli that were low in association value and high in visual similarity (complexity and overall form), a significant positive correlation between the two measures $[\mathrm{r}=.57 ; \mathrm{t}(22)=3.95, \mathrm{p}<.01]$ negated that strategy. Since evaluation of familiarity was the primary goal of the study, it was decided that association value was the more critical feature. Thus, only forms for which at least $60 \%$ of the subjects gave no association were chosen for stimuli. The 12 resulting forms are shown in Figure 1.

The letter stimuli had low visual confusability (Townsend, 1971) and appeared different when rotated $180 \mathrm{deg}$. The 12 letters in both the rotated and unrotated conditions were A, C, D, E, F, G, K, L, P, S, V, and Y. All stimuli were printed in black ink on white cards and then photocopied to eliminate any subtle differences between any pair of "same" pairings. In all conditions, the stimuli were paired randomly to produce 12 "same" and 12 "different" pairs. The 24 pairs defined a trial.

The stimuli were presented in a three-channel tachistoscope. Each stimulus subtended a visual angle of $28 \mathrm{~min}$ at $125 \mathrm{~cm}$ and was displaced $45 \mathrm{~min}$ on either side of a central fixation point. In the simultaneous conditions, each stimulus pair was presented for $100 \mathrm{msec}$. In the successive conditions, each element of a pair was exposed for $100 \mathrm{msec}$, with an intervening interelement interval of $1 \mathrm{sec}$ during which the observer viewed the fixation point.

\section{Subjects}

The observers were 48 students from the introductory psychology course who received course credit for participation. Each observer had at least 20/25 corrected or uncorrected near vision as indicated by an Ortho-Rater.

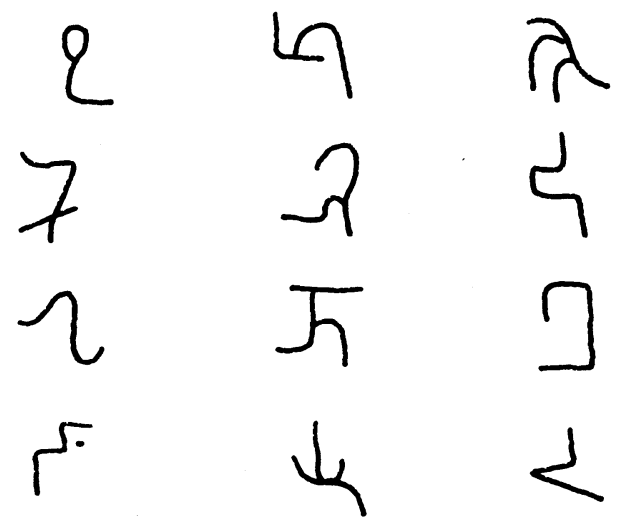

Figure 1. Nonsense forms.

\section{Design and Procedure}

Eight observers each were assigned randomly to one of the six combinations of three stimulus types (letter, rotated letters, nonsense forms) and two presentation modes (simultaneous and successive). Each observer received three trials of the 24 "same" and "different" pairs (12 each) appropriate to his or her condition. Across all observers, all possible orders of pairs within a trial were presented.

The observers were read instructions that asked them to decide whether the elements of each pair were the "same" or "different" and then to respond as quickly as possible without sacrificing accuracy by moving an appropriately labeled toggle switch. Labeling of the switches was counterbalanced across observers in each condition. A millisecond timer started at the onset of the stimulus pair (the first element of a pair in the successive conditions) and terminated with the observer's response.

The observers were given preliminary practice with the response switches and at least 10 practice trials with digit stimuli and the appropriate presentation mode. When an observer was responding without errors and indicated she or he was comfortable with the task, the type of stimulus she or he would be viewing was announced and the experiment was begun.

All presentations were initiated by the observer, resulting in a variable intertrial interval. Each observer required approximately $40 \mathrm{~min}$ to complete the experiment. No performance feedback was given, but the observers were verbally encouraged and reassured throughout the session.

\section{RESULTS}

Table 1 shows mean reaction times (RTs), their standard deviations, and percent errors as a function of the four experimental variables: stimulus type, presentation mode, trials, and same vs. different pairs. Each mean RT is based on eight observers. To compensate for the interelement interval $(1 \mathrm{sec})$ and the duration of the second element of a stimulus pair $(100 \mathrm{msec})$, $1,100 \mathrm{msec}$ was deducted from all RTs in the successive conditions. Percent errors are based on the 12 same or 12 different pairs seen by the observers on each trial.

The percentage of errors ranged from $0 \%$ to $16 \%$, with the greatest number produced by the nonsense forms. The average error rates were $.01, .01$, and .04 for the letters, rotated letters, and nonsense forms, respectively. Across all types of stimuli, significantly more errors were made for "same" than for "different" judgments $\left[\chi^{2}(1)=34.8, p<.005\right]$. Although the error rates were not consistent, it is clear that incorrect responses were associated with longer RTs, regardless of experimental condition. Correct responses averaged $698 \mathrm{msec}$ and incorrect responses averaged $1,148 \mathrm{msec}$, a statistically reliable difference $[\mathrm{t}(3456)=6.72$, $\mathrm{p}<.001]$. Since a primary concern of the study was task difficulty and since errors as well as RT reflect difficulty, RTs of incorrect responses were included in the subsequent analyses.

The RT data were evaluated by means of a four-way ANOVA, with two between-subjects factors (stimulus type and presentation mode) and two within-subjects factors (trials and type of stimulus pair). The results demonstrated that there was a significant decline in RT over trials for each of the three stimulus types 
Table 1

Mean Reaction Times and Standard Deviations (in Milliseconds) and Percent Errors (PE)

\begin{tabular}{|c|c|c|c|c|c|c|c|c|c|c|c|c|}
\hline \multirow[b]{3}{*}{ Statistic } & \multicolumn{6}{|c|}{ Simultaneous Presentation } & \multicolumn{6}{|c|}{ Successive Presentation } \\
\hline & \multicolumn{2}{|c|}{ Trial 1} & \multicolumn{2}{|c|}{ Trial 2} & \multicolumn{2}{|c|}{ Trial 3} & \multicolumn{2}{|c|}{ Trial 1} & \multicolumn{2}{|c|}{ Trial 2} & \multicolumn{2}{|c|}{ Trial 3} \\
\hline & Same & Different & Same & Different & Same & Different & Same & Different & Same & Different & Same & Different \\
\hline & \multicolumn{12}{|c|}{ Letters } \\
\hline $\begin{array}{l}\text { Mean } \\
\text { SD } \\
\text { PE }\end{array}$ & $\begin{array}{r}705 \\
193 \\
2\end{array}$ & $\begin{array}{r}609 \\
85 \\
0\end{array}$ & $\begin{array}{r}640 \\
192 \\
5\end{array}$ & $\begin{array}{r}630 \\
115 \\
0\end{array}$ & $\begin{array}{r}654 \\
203 \\
2\end{array}$ & $\begin{array}{r}607 \\
137 \\
0\end{array}$ & $\begin{array}{r}717 \\
214 \\
1\end{array}$ & $\begin{array}{r}760 \\
185 \\
0\end{array}$ & $\begin{array}{r}632 \\
180 \\
1\end{array}$ & $\begin{array}{r}692 \\
216 \\
1\end{array}$ & $\begin{array}{r}610 \\
221 \\
1\end{array}$ & $\begin{array}{r}619 \\
184 \\
0\end{array}$ \\
\hline $\mathrm{PE}$ & \multicolumn{12}{|c|}{ Rotated Letters } \\
\hline $\begin{array}{l}\text { Mean } \\
\text { SD } \\
\text { PE }\end{array}$ & $\begin{array}{r}726 \\
123 \\
2\end{array}$ & $\begin{array}{r}682 \\
134 \\
0\end{array}$ & $\begin{array}{r}625 \\
90 \\
2\end{array}$ & $\begin{array}{r}622 \\
104 \\
0\end{array}$ & $\begin{array}{r}619 \\
138 \\
2\end{array}$ & $\begin{array}{r}610 \\
120 \\
0\end{array}$ & $\begin{array}{r}684 \\
202 \\
0\end{array}$ & $\begin{array}{r}763 \\
271 \\
2\end{array}$ & $\begin{array}{r}626 \\
249 \\
0\end{array}$ & $\begin{array}{r}656 \\
211 \\
0\end{array}$ & $\begin{array}{r}551 \\
224 \\
1\end{array}$ & $\begin{array}{r}576 \\
188 \\
2\end{array}$ \\
\hline & \multicolumn{12}{|c|}{ Nonsense Forms } \\
\hline $\begin{array}{l}\text { Mean } \\
\text { SD } \\
\text { PE }\end{array}$ & $\begin{array}{r}969 \\
326 \\
16\end{array}$ & $\begin{array}{r}960 \\
269 \\
3\end{array}$ & $\begin{array}{r}913 \\
266 \\
15\end{array}$ & $\begin{array}{r}810 \\
146 \\
12 \\
\end{array}$ & $\begin{array}{r}794 \\
240 \\
5\end{array}$ & $\begin{array}{r}816 \\
216 \\
1 \\
\end{array}$ & $\begin{array}{r}811 \\
287 \\
2 \\
\end{array}$ & $\begin{array}{r}843 \\
232 \\
2 \\
\end{array}$ & $\begin{array}{r}746 \\
288 \\
0 \\
\end{array}$ & $\begin{array}{r}769 \\
284 \\
0 \\
\end{array}$ & $\begin{array}{r}717 \\
287 \\
2 \\
\end{array}$ & $\begin{array}{r}722 \\
275 \\
0 \\
\end{array}$ \\
\hline
\end{tabular}

$[F(2,84)=34.17, p<.001]$. The absence of an interaction between trials and stimulus type indicated that the same proportional decline occurred with each type of stimulus. Judgments of the nonsense forms required more time than those for the letters or rotated letters $[F(2,42)=4.14, p<.025]$. A Duncan test indicated that RTs for the letters and rotated letters did not differ. A marginally significant interaction between presentation mode and type of stimulus pair $[\mathrm{F}(1,42)=$ $3.61, p<.07]$ supports the finding that judgments of "same" pairs were made somewhat faster in the successive than in the simultaneous conditions. For the "different" pairs, RTs were about the same under both presentation modes. No other main effects or interactions were reliable. However, it is noteworthy that RTs for the unfamiliar nonsense forms did not increase with the presumed memory demand of the successive conditions; in fact, performance with the forms was somewhat better under the successive conditions. Finally, RTs for "same" and "different" pairs did not vary for any of the three stimulus types, indicating that familiarity had no differential effect on the type of stimulus pair.

\section{DISCUSSION}

Like other investigations of familiarity in matching tasks, the present experiment also produced results not in complete accord with earlier findings. To begin on a positive note, the lack of difference in the "same" and "different" RTs for letters and rotated letters replicates Ambler and Proctor's (1976) finding that "same" and "different" judgments are not influenced by familiar and unfamiliar stimuli when each type of stimulus is presented separately in blocked trials. In contrast, both Ambler and Proctor and Egeth and Blecker (1971) found that familiarity facilitated "same" but not "different" judgments when familiar and unfamiliar letters were presented together in mixed trials. In addition, the lack of difference between the letters and rotated letters in the present study appears to be independent of trials, presentation mode, and type of stimulus pair, since none of these factors interacted with type of stimulus in a separate ANOVA based only on letters and rotated letters.

The finding that RTs for the nonsense forms were significantly longer than those of the letters is contrary to the equally fast physical matching of letters and Gibson figures observed by Posner and Mitchell (1967). The present results suggest that familiarity and meaningfulness have different perceptual effects, a distinction analogous to that made by Noble (1963) in his analysis of CVCs. Rotated letters are unfamiliar but, nevertheless, highly meaningful, whereas nonsense forms are neither familiar nor meaningful. In their levels-of-processing model, Posner and Mitchell have argued that physical matches should be made more quickly than name or identity matches. If true, there should have been no difference between the letter stimuli and nonsense forms in the present study when both elements of a pair were present for comparison. Given the present results, it thus seems highly likely that meaningfulness, in the sense of having a readily available verbal label, facilitates perceptual matching.

The failure to obtain a significant difference between the simultaneous and successive conditions does not in itself rule out a verbal facilitation hypothesis. Given this hypothesis, performance of the nonsense forms should have declined with imposition of the memory demand of successive presentation and that of the letters should not have changed. In fact, RTs of the nonsense forms were $100 \mathrm{msec}$ faster under the successive conditions. Since a masking field was not available to fill the interval between stimuli in the successive conditions, the observers had ample opportunity to process the first stimulus during the 1-sec interstimulus interval.

The main effect of presentation mode was not significant, but the ANOVA demonstrated that it differentially influenced the RTs of the "same" and "different" pairs. "Same" responses were slightly slower than "different" responses in the simultaneous conditions, and vice versa in the successive conditions. Since this pattern was consistent across types of stimuli, it is clearly independent of familiarity. According to Hock's (1973) model of structural and analytical processes, a search for difference is optimized under simultaneous conditions because the short exposure $(100 \mathrm{msec})$ allows little opportunity to structure the input. With successive presentation, the absence of a masking field provides sufficient time to consolidate the first element of a stimulus pair and create or access a suitable structural or schematic representation and, thus, favor a "same" response. Such microprocessing seems compatible with the thesis that 
the observer will use a previously learned verbal iabel if one is available.

\section{REFERENCES}

Amble r, B. A., \& Proctor, J. D. The familiarity effect for single-letter pairs. Journal of Experimental Psychology: Human Perception and Performance, 1976, 2, 222-234.

Egeth, H., \& Blecker, D. Differential effects of familiarity on judgments of sameness and difference. Perception \& Psychophysics, 1971, 9, 321-326.

HeвB, D. O. Textbook of psychology (3rd ed.). Philadelphia: Saunders, 1972.

Hochвerg, J. In the mind's eye. In R. N. Haber (Ed.), Contemporary theory and research in visual perception. New York: Holt, Rinehart, \& Winston, 1968.

Носк, H. S. The effects of stimulus structure and familiarity on same-different comparisons. Perception \& Psychophysics, 1973, 14, 413-420.
KRUEGER, L. E. Effect of letter-pair frequency and orientation of speed of "same"." "different" judgments by children and adults. Bulletin of the Psychonomic Society, 1973, 2, 431-433.

KRUEGER, L. E. Familiarity effects in visual information processing. Psychological Bulletin, 1975, 82, 949-974.

Noble, C. E. Meaningfulness and familiarity. In C. N. Cofer \& B. S. Musgrave (Eds.), Verbal behavior and learning: Problems and processes. New York: McGraw-Hill, 1963.

Posner, M. I., \& Mitchell, R. F. Chronometric analysis of classification. Psychological Review, 1967, 74, 392-409.

Robinson, J. S. Familiar patterns are no easier to see than novel ones. American Journal of Psychology, 1969, 82, 513-522.

Townsend, J. T. Theoretical analysis of an alphabetic confusion matrix. Perception \& Psychophysics, 1971, 9, 40-50.

(Received for publication November 13, 1980.) 